\title{
Transdermal patches: Design and current approaches to painless drug delivery
}

\author{
OTHMAN A. AL HANBALI ${ }^{1,2 *}$ \\ HAJI MUHAMMAD SHOAIB KHAN ${ }^{3}$ \\ MUHAMMAD SARFRAZ ${ }^{4,5}$ \\ MOSAB ARAFAT ${ }^{4}$ \\ SHAKEEL IJAZ ${ }^{3}$ \\ ABDUL HAMEED ${ }^{3}$ \\ ${ }^{1}$ Faculty of Pharmacy, The University \\ of Sydney, Sydney NSW 2006, Australia \\ ${ }^{2}$ Dana Pharmaceuticals Factory, Zawata \\ Road, Nablus-West Bank, Palestinian \\ Authority \\ ${ }^{3}$ Department of Pharmacy, Faculty \\ of Pharmacy and Alternative Medicine \\ The Islamia University of Bahawalpur \\ Pakistan
}

${ }^{4}$ College of Pharmacy, Al Ain University of Science and Technology, Al Ain PO Box 64141, Al Ain, Abu Dhabi, UAE

${ }^{5}$ Faculty of Pharmacy and Pharmaceutical Sciences, University of Alberta

Edmonton, AB T6G 2E1 Canada

Accepted November 7, 2018

Published online November 28, 2018

\begin{abstract}
Use of transdermal patches can evade many issues associated with oral drug delivery, such as first-pass hepatic metabolism, enzymatic digestion attack, drug hydrolysis and degradation in acidic media, drug fluctuations, and gastrointestinal irritation. This article reviews various transdermal patches available in the market, types, structural components, polymer role, and the required assessment tools. Although transdermal patches have medical applications for smoking cessation, pain relief, osteoporosis, contraception, motion sickness, angina pectoris, and cardiac disorders, advances in formulation development are ongoing to make transdermal patches capable of delivering more challenging drugs. Transdermal patches can be tailored and developed according to the physicochemical properties of active and inactive components, and applicability for long-term use. Therefore, a number of chemical approaches and physical techniques for transdermal patch development are under investigation.
\end{abstract}

Keywords: transdermal patch, transdermal drug delivery, polymer matrix, adhesives, skin formulation

\section{INTRODUCTION}

Development of a safe and efficient drug delivery system is the aim of every pharmaceutical researcher and industry (1). Transdermal route of drug delivery can achieve local and systemic therapeutic effects (2). Transdermal drug delivery is an attractive substitute for oral drug administration as it bypasses first pass metabolism, gastrointestinal effects and, moreover, it can overcome the poor patient compliance associated with other drug delivery routes (3-6). Transdermal drug delivery is self-administered, allowing the drug to pass through intact skin over a controlled period of time to achieve a local or systemic

\footnotetext{
*Correspondence; e-mail: otal8872@uni.sydney.edu.au
} 
Table I. Drug product and clinical use of transdermal patches on the current market

\begin{tabular}{lll}
\hline Drug & Product name & Clinical use \\
\hline Scopolamine & Transderm-Scop & Motion sickness \\
Nitroglycerin & Transderm-Nitro & Angina pectoris \\
Clonidine & Catapres-TTS & High blood pressure \\
Estradiol & Estraderm & Menopause \\
Fentanyl & Duragesic & Chronic pain \\
Nicotine & Nicoderm & Smoking cessation \\
Testosterone & Testoderm & Testosterone low level \\
Lidocaine/epinephrine & Iontocaine & Pain relief \\
Estradiol/norethidrone & Combipatch & Menopause \\
Lidocaine & Lidoderm & Pain relief \\
Norelgestromin & Ortho Evra & Contraception \\
Estradiol/levonorgestrel & Climara Pro & Menopause \\
Oxybutynin & Oxytrol & Overactive bladder \\
Lidocaine (ultrasound) & SonoPrep & Pain relief \\
Lidocaine/tetracaine & Synera & Pain relief \\
Fentanyl HCl & Ionsys & Postoperative pain \\
Methylphenidate & Daytrana & ADHD \\
Selegiline & Emsam & Depression \\
Rotigotine & Neupro & Parkinson's disease \\
Rivastigmine & Exelon & Dementia \\
\hline
\end{tabular}

effect (2). Drugs can be delivered through transdermal patches in dissolved lipid based form enabling them to produce the required efficacy $(7,8)$.

The first transdermal system containing scopolamine was approved in the United States in 1979; the US Food and Drug Administration (FDA) approved nicotine patches in 1984 (9). A decade later, transdermal patches for pain relief, analgesic activity, contraception, and hormone replacement therapy were FDA approved and marketed (10), and the progress in this field continues today. Table I shows some transdermal patch products currently on the US market $(2,9,11-13)$.

Transdermal drug delivery systems evade a variety of issues associated with other routes of drug administration, such as first-pass hepatic metabolism, enzymatic digestion, drug hydrolysis in acidic environments, gastrointestinal irritation, drug fluctuations, adverse effects and therapeutic failure, and disease transmission risk. Further advantages include patient compliance, low cost, and controlled drug release (14). Limitations to transdermal drug delivery include the possibility of skin irritation, macromolecular agents and that ionic drugs cannot be delivered, and it is not suitable for patients in shock or with low peripheral blood flow $(14,15)$. Classification of transdermal drug delivery systems has proceeded through three generations on the basis of drug molecule size and the presence 
of penetration enhancer materials $(11,16)$. In the first generation, small drug molecules could be topically applied without using transdermal penetration enhancing agents. In the second generation, transdermal enhancing agents were added to enhance the penetration of topically applied small drug molecules. Macromolecule penetration was enabled in topically applied medication in the third generation. Physicochemical properties, chemical nature, strength, molecular weight, ionization degree, drug partition coefficients, and the hydrophile-lipophile balance (HLB) of polymers are parameters that should be considered in transdermal patch development (17-22).

Transdermal drug delivery systems can be modified using a number of permeation enhancer materials so that the drug absorption profile can be controlled in a predictable manner. Various transdermal drug delivery systems have different mechanisms to control the drug release rate, such as single layer or multilayer drugs in the adhesive system, vapour patch, membrane moderated, microreservoir transdermal systems, matrix systems containing drug-in-adhesive or matrix-dispersion systems. Therefore, the present review contains a brief description of various types of transdermal patches available on the market with FDA approval, their structural components, ingredient physicochemical properties, designs, method of preparations, polymeric matrix components and various evaluation methods required for the assessments. FDA approved transdermal patches available on the current market are described below.

\section{TYPES OF TRANSDERMAL PATCHES}

\section{Single layer drug-in-adhesive patches}

In Fig. 1, a single layer of polymer with adhesive properties is used as a reservoir for drug dispersion. An impermeable backing laminate is placed beneath the single layer. The drug is deposited in and adheres to the single polymer layer, and is released from the backing laminate layer that supports the drug reservoir (23). The transdermal product Daytrana ${ }^{\circledR}$ is an example of a single layer drug-in-adhesive transdermal patch containing methylphenidate.

\section{Multilayer drug-in-adhesive patches}

Multilayer transdermal patches consist of a drug reservoir layer and an adhesive layer where drug release is controlled over a period of time (24-25). A temporary protective layer and a permanent backing laminate are included in multilayer systems. Multilayer patches are used to deliver pain medication, drugs that encourage smoking cessation, and hormone therapy; drug delivery can be prolonged for up to seven days.

\section{Vapor transdermal patches}

Vapor transdermal patches consist of a single layer of adhesive polymer with a vapor release property where vapor can be released (24-25). A number of vapor dermal patches are available on the market and are used for different purposes. For example, nicoderm $\mathrm{CQ}^{\circledR}$ are nicotine vapor transdermal patches containing essential oils that, when released, can help quit smoking. This product was introduced to the European market in 2007. Al- 
tacura $^{\circledR}$ vapor patches are another type of vapor patches containing essential oils that can be used in cases of decongestion. Another type of vapor patches as anti-depressant medications or sedatives are also available on the market (Table I).

\section{Membrane moderated transdermal reservoir patches}

Fig. 1 shows a transdermal patch containing a drug reservoir, a backing layer made of impermeable metallic plastic laminate, and a porous polymeric membrane that controls drug release over time. The membrane is made of polymeric materials (e.g., hypoaller-
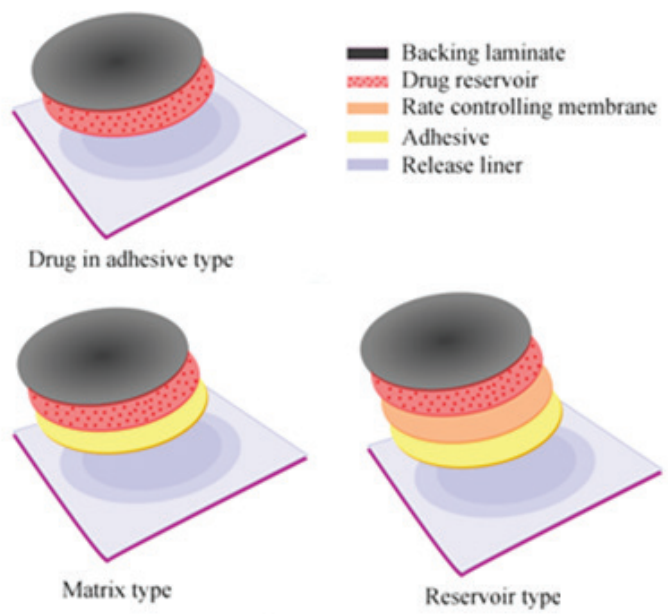

Fig. 1. Schematic diagram of various types of transdermal patches.

genic adhesive polymer, ethylene vinyl acetate copolymer). Drug in the transdermal patch is controlled by molecular dispersion of the drug in a polymer matrix part of the preparation $(26,27)$. Commercial transdermal patches with modified drug release include Transderm-Nitro ${ }^{\circledR}$ containing nitroglycerin for one-day application, Transderm-Scop ${ }^{\circledR}$ containing scopolamine for three-day application, and Catapres ${ }^{\circledR}$ containing clonidine for seven-day application (Table I).

\section{Microreservoir transdermal patches}

Microreservoir transdermal patches combine matrix dispersion with a drug reservoir. The reservoir is prepared by suspending the drug in an aqueous solution of hydrophilic polymer, then homogeneously dispersing the drug suspension on a lipophilic polymer. Dispersion is carried out with a high shear mechanical force, which results in the formation of thousands of microscopic, unleachable spheres. The drug release profile follows a zero order rate of kinetic drug release, maintaining a constant drug level in the plasma. Crosslinking polymeric agents are usually added, since the drug dispersion needs to be thermodynamically stable $(25,28)$. 
Table II. FDA approved other transdermal delivery systems

\begin{tabular}{lll}
\hline Drug & Product name & Transdermal delivery system \\
\hline Flurandrenolide & Cordran $^{\circledR}$ Tape & Transdermal tape \\
Testosterone & AndroGel $^{\circledR}$ & Transdermal gel \\
Estradiol & Evamist $^{\circledR}$ & Transdermal spray \\
Fentanyl HCl & IONSYS $^{\circledR}$ & Iontophoretic patch \\
Insulin & Vyteris insulin patch $^{\circledR}$ & Iontophoretical patch \\
Hydrocortisone & Tegaderm patch & Electrophotophoresis \\
\hline
\end{tabular}

\section{Matrix system: drug-in-adhesive}

Using single layer or multilayer transdermal patches, the drug reservoir is designed to distribute the drug on an adhesive polymer, as shown in Fig. 1. This drug-polymer matrix is placed onto an impermeable backing layer either by solvent casting or by melting the adhesive polymeric materials (29). A number of commercial products of this type of transdermal patch are available on the market; for example, the Climara ${ }^{\circledR}$ transdermal $^{2}$ patch contains 100 micrograms of estradiol for one-day application, and the NicoDerm ${ }^{\circledR}$ CQ transdermal patch contains nicotine to encourage smoking cessation for up to 10 weeks (Table I).

\section{Matrix systems: Matrix-dispersion}

In a matrix transdermal patch, the reservoir is a hydrophilic or lipophilic polymer matrix and the drug is homogenously dispersed in the matrix (30) by placing the drug-polymer matrix over a plate with an impermeable laminate backing. Commercial products of matrix dispersion patches such as Nitro-Dur ${ }^{\circledR}$, which contains nitroglycerin and minitran, provide a continuous drug flow through intact skin (Table I).

\section{Miscellaneous transdermal patches}

Other FDA approved transdermal matrix delivery systems are transdermal patches with adhesive tapes, transdermal gel, transdermal spray, iontophoretic delivery, and phonophoresis delivery, as shown in Table II.

\section{STRUCTURAL COMPONENTS OF TRANSDERMAL PATCHES}

\section{Drug selection}

In order to design transdermal patches, the physicochemical properties of drugs need to be considered. Hydrophobicity and ionization status are essential factors in drug selection as they influence skin penetration (14), determining drug solubility and diffusivity through the stratum corneum layer of the skin (31). Other physicochemical properties of the drug that have a direct effect on skin penetration are the melting point (MP), partition 
coefficient $(\log P)$, aqueous solubility, molecular size and molecular weight (MW), dose concentration and saturation, permeability, absorbability, and diffusivity across the stratum corneum of human skin (32-33). Most transdermal patches contain lipophilic drugs, that is, above the lower Berner-Cooper boundary of $M W=500,<1000$ Daltons, $\log P$ range from 1 to 5, and $\mathrm{MP}<250{ }^{\circ} \mathrm{C}$. For example, fentanyl has moderate MW (337 Da), low MP $\left(83^{\circ} \mathrm{C}\right)$, and moderate to high lipophilicity $(\log P=3.9)(9)$. Drugs with low dose strength, short half-life, facile hydrolysis in acidic media, and those subject to hepatic metabolism, can evade the above mentioned issues when delivered by transdermal patches $(24,32,33)$.

\section{Polymer matrix characteristics}

Polymers control the drug release rate from the drug reservoir in the transdermal patch, allowing a safe, constant, and effectual drug delivery to the body (34). Companies that market transdermal patches often focus on the development of a specific polymeric system. Alza Corporation specializes in microporous polypropylene and ethylene vinyl acetate (EVA) copolymers. Searle Pharmacia emphasizes silicone rubber $(35,36)$. Sigma fabricates isosorbide dinitrate matrixes using ethylcellulose. Colorcon, in the United Kingdom, employs hydroxy propyl methylcellulose (HPMC) in matrix preparation for propranolol transdermal delivery (37).

Table III. Transdermal patch composition

\begin{tabular}{llll}
\hline Polymer & Drug & Type of system & Reference \\
\hline HPMC & Propranolol & Matrix & 39 \\
HPMC & Hydrocortisone & Gel & 40 \\
Silicone elastomers (MDX4-421) & L-Timolol maleate & Matrix & 41 \\
Carboxy vinyl & L-Dopa & Gel & 42 \\
Acrylic adhesives & Tacrine & Drug-in-adhesive & 43 \\
Ethyl cellulose T-50 & Isosorbide dinitrate & Matrix & 44 \\
Cariflex TR-1107 & Dihydroetorphine & Drug-in-adhesive & 45 \\
Acrylic PSA & Nicotine & Drug-in-adhesive & 46 \\
HPMC & Nicorandil & Reservoir & 47 \\
HPMC & Nimodipine & Membrane moderated & 48 \\
HPMC/ Eudragit RL100 & Carvedilol & Reservoir & 49 \\
HPMC/ Chitosan & Etoricoxib & Matrix & 50 \\
Acrylic adhesives & Rivastigmine & Drug-in-adhesive & 51 \\
DURO-TAK ${ }^{\circledR}$ adhesives & Indapamide & Drug-in-adhesive & 52 \\
HPMC/ MC/ PVP & Celecoxib & Matrix & 53 \\
Acrylic adhesives & Meloxicam & Drug-in-adhesive & 54 \\
HPMC/ PVP/ CP & Glibenclamide/ Atenolol & Matrix & 55 \\
Acrylic / Silicone polymer & Diclofenac Diethylamine & Drug-in-adhesive & 56 \\
\hline
\end{tabular}

HPMC - hydroxypropyl methyl ether; MC - methyl cellulose; PVP - polyvinylpyrrolidone; CP - carbopol 


\section{Polymers in transdermal patch matrix formation}

Polymers employed in transdermal patch formulation have various functions, such as matrix formation, drug delivery rate control, pressure sensitive adhesives, backing laminates, and protective drug release liners. They should be biocompatible with the skin, and should render a constant and effectual supply of the drug throughout the delivery period advertised by the manufacturer (38). Polymer use in transdermal patch formulations and the corresponding references are shown in Table III.

Polymer selection is critical in the design of a polymer matrix because the polymer affects the release properties of the drug, the adhesion/cohesion balance, and the stability of the product and its compatibility with other product constituents and the skin of the recipient (57). Several polymers used in transdermal patch matrix formation are described below.

Polyethylene glycol. - Polyethylene glycol (PEG) has a wide range of biomedical applications because PEG has excellent biocompatibility. The polymeric network obtained by crosslinking PEG with tris(6-isocyanatohexyl)isocyanurate, with the help of the aurethane-allophanate bond, has the ability to swell and form gels in phosphate buffered ethanol or saline. This system releases solutes in a biphasic mode (58).

Acrylic-acid matrices. - Acrylic acid matrices along with plasticizers are widely used in the fabrication of the drug polymer matrix for transdermal patches. Examples of such polymers are Eudragit S100, Eudragit E100, Eudragit RS PM, and Eudragit RL PM (59). Eudragit NE 40 D, a nonadhesive copolymer of ethyl acrylate and methyl methacrylate, is used as a matrix forming agent in transdermal patches (60).

Cellulose derivatives. - Ethyl cellulose and polyvinylpyrrolidone (PVP) with dibutyl phthalate $(30 \%)$ as a plasticizer matrix have been used to fabricate diltiazem $\mathrm{HCl}$ and indomethacin patch systems. To improve the drug release rate, a water soluble polymer such as PVP is added to water insoluble films to form polymers such as ethyl cellulose. The high drug release rate is due to the leaching of water soluble constituents, which results in pore formation (61).

Hydroxypropyl methylcellulose (HPMC). - HPMC is a water soluble polymer that swells by absorption of water. It is widely used in oral controlled release drug delivery systems. It has been tested as a matrix forming agent for propranolol transdermal formulations. HPMC forms clear films, since the drug is very soluble in the polymer. HPMC matrices show fast drug release due to the burst effect during dissolution testing. This is attributed to the easy hydration and swelling of the polymer in the matrices (39).

Pressure sensitive adhesives (PSA). - Adhesive characteristics of transdermal patch preparations are crucial to transdermal devices. There should be a complete and intimate contact between the patch and skin surface for efficient delivery of the drug. This contact is attributed to interatomic and intra-molecular attractive forces that PSAs establish with the skin (60). PSAs are viscoelastic chemical substances that adhere to the skin with low pressure application (62). PSAs need to deform under pressure to attain the required degree of contact (63). PSAs adhere to the skin with no more than applied finger pressure, they are aggressively and permanently sticky, they exert a strong holding force, and they can be removed from a smooth surface without leaving a residue. Most adhesives used in transdermal patches 
are polyisobutylene, acrylic, and silicone based (63). Adhesion is enabled by a liquid-like flow of adhesive material that wets the skin surface when pressure is applied. Adhesion takes place when elastic energy is stored during the bond breaking process. Hence, viscoelastic materials have the characteristics of pressure sensitive adhesion, and it is the balance between elastic energy and viscous flow that determines the practicability of the material (35). Natural rubber, acrylics, thermoplastic elastomers, polyisobutylene, and silicone based adhesives are generally used in transdermal patch designs (64). The choice of a suitable adhesive involves factors such as drug formulation, patch design, and compatibility with other patch constituents and the skin (35). Polyacrylics are water soluble, biodegradable, polyester based polymers formed by the polymerization of an alkyl acrylate ester. Polyacrylics are widely used in the pharmaceutical industry, especially as adhesives in the preparation of transdermal patches. They form liquids at $\mathrm{pH} 5$ and gels at $\mathrm{pH} 7$ (65). Their mechanical characteristics improve as their molecular weight increases (63). Polyisobutylene (PIB) is a vinyl polymer formed by the cationic polymerization of an isobutylene monomer. PIB is a colorless, semisolid elastic substance with very low moisture and air permeability. It has good thermal and oxidative stability (66). Its physical characteristics change with an increase in molecular weight. Low MW polymers are less viscous than high MW polymers (35). Pressure sensitive adhesives are gaining more importance because they are solvent free, environmentally friendly, and are easy to produce. They are prepared from thermoplastic materials, plasticizers, and Escorez ${ }^{\mathrm{TM}}$ tackifying resins. They are suitable for the fabrication of matrix patches owing to their high drug loading capacity and strong cohesiveness (67).

Rate controlling membrane. - In a transdermal patch, the active agent diffuses through an inert membrane at a finite and controlled rate. The dosage rate per patch area is controlled by altering the composition and thickness of the inert membrane (35).

Ethylene vinyl acetate (EVA). - Ethylene vinyl acetate (EVA) is often used to prepare rate controlling membranes for transdermal patches. The permeability of the membrane can be altered by adjusting the percentage of vinyl acetate in the polymer (35).

Silicone rubber. - Silicone rubber is an elastomer (rubber-like material) composed of silicone, itself a polymer, along with carbon, hydrogen, and oxygen. It is often used in rate controlled devices because it is biocompatible, easily obtained, and permeable to many drugs, especially steroids. The high permeability of steroids is due to free rotation around the silicone rubber backbone which is responsible for the low microscopic viscosity in the polymer (35).

Polyurethane. - Polyurethanes (PU) are polymers formed by the condensation of polyols (organic compounds containing multiple hydroxyl groups) and urethane. Polyurethanes made from polyester and polyols are called polyester urethanes whereas polyurethanes made from polyether and polyols are called polyether urethanes. Because of their resistance to hydrolysis, most urethanes used in transdermal patches are polyether urethanes (35). However, polyester urethanes have gained attention due to their biodegradable nature (35). Urethane polymers are rubbery and permeable. Their permeability can be increased by adjusting the hydrophilic and hydrophobic ratios of the incorporated polymers (68). Polyurethane membranes are suitable for passing hydrophilic compounds, which have low permeability in hydrophobic silicone or EVA membranes (69). 
Release liner. - A transdermal patch is covered with a layer of protective material, which is removed immediately before the patch is applied to the skin. This layer is a part of primary packaging (38). Because of intimate contact of the liner with the dosage form, it should also meet all the requirements concerning the inertness to the constituents of the delivery system and penetration properties (41). Fluorpolymers, fluoroolefin-based polymers, and linear fluoroacrylates are commonly used to manufacture a release liner; e.g., BIO PSA HighTack 7-4301, BIO PSA MediumTack 7-4201, Scotch Pak 1022, Scotch Pak 1006 (70, 71).

Backing laminate. - The material of the backing layer should be chemically resistant and inert to other constituents in the delivery system. Furthermore, it should hinder the leaching of additives. An efficient backing layer is flexible and facilitates the transmission of oxygen and moisture. Examples include silicone oil, EVA, Polyisobutylene, 3M Scotchpak Backing 1006 (72).

Penetration enhancers. - Stratum corneum offers the main barrier function of the skin (73). Penetration (or permeation) enhancers are chemical compounds that efficiently and reversibly weaken the stratum corneum barrier properties, allowing drugs to penetrate to deeper layers of the skin and reach the systemic circulation (74). Many chemical compounds have been tested in order to discover more efficient and inert permeation enhancers to employ in transdermal patches. About 360 chemical compounds have known permeation enhancing ability (75), and skin permeability is enhanced by many different mechanisms. Some chemicals interact with the skin and solubilize lipids within the stratum corneum, others hydrate the stratum corneum, and many others increase the fluidity of intercellular lipids in the stratum corneum. Increased fluidity in the stratum corneum results in increased skin permeability (76). Permeation enhancing compounds include terpenes, sulphoxides, pyrrolidones, laurocapram, fatty acids, alcohols, fatty alcohols, surfactants, glycols, urea, and bile salts (77-79).

Other excipients. - Solvents used in transdermal patch preparation include methanol, ethanol, dichloromethane, and acetone. Solvents are used in the drug reservoir. Plasticizers such as dibutylpthalate and triethylcitrate are used in concentrations ranging from 5-20\% $(80,81)$ to add plasticity to transdermal patches $(80)$. Phosphate esters and glycol derivatives (polyethylene glycol, propylene glycol) are also used for plastification of the polymeric films in transdermal patches (81).

\section{CHARACTERIZATION AND ASSESSMENT TOOLS FOR TRANSDERMAL PATCH PREPARATION}

A number of assessment and evolution tests should be performed in order to descript and characterize transdermal patches such as dissolution, in vitro drug release, in vitro skin permeation, adhesive properties and control of excipients. These tests are mentioned below and they comply with the European Medicines Agency Guidelines on the quality of transdermal patches made by the Committee for Medicinal Products for Human Use (82). Moreover, other types of physical, chemical and biological tests, evaluation and assessments explained below should be performed such as interaction of materials, patch thickness, weight uniformity, folding endurance, moisture content, moisture uptake or weight gain, water vapor permeability, drug content, flatness, stability, swellability and skin irritation tests. 


\section{Drug-polymer interaction studies}

Interactions between drugs and polymers in a lipid matrix can be determined using a number of thermal and physico-analytical techniques (82-84), such as differential scanning calorimetry (DSC), Fourier transform infrared spectroscopy (FTIR), X-ray powder diffractometry (XRPD), nuclear magnetic resonance (NMR) spectroscopy, and infrared (IR) radiation. Identification of components in a eutectic drug-polymer mixture is possible because each chemical has a unique peak in DSC, IR, and NMR spectra. To observe interactions between cell surface and polymer, a florescence agent is attached to the polymer, the complex is incubated with cells, and the polymer-cell complex is visualized under a confocal microscope. NMR can be used to clarify the effect of the polymer on lipid membrane fluidization/stabilization.

\section{Patch thickness}

Patch thickness is calculated by taking readings at three to five places on the patch with a digital micrometer screw gauge. Mean thickness and standard deviation of such multiple readings are determined to make sure that patch thickness is appropriate $(85,86)$.

\section{Weight uniformity}

Weight uniformity is determined by weighing 10 individual, randomly selected patches, and calculating the average weight and standard deviation. Individual patch weight must not vary to a large extent from the average weight (87).

\section{Folding endurance}

When a particular area of patch is sliced evenly and repeatedly folded at an identical point until it breaks, folding endurance is the number of times the film is folded without breaking (85).

\section{Moisture content}

To calculate the moisture content of a transdermal patch, the patch is accurately weighed, placed in a desiccator with fused calcium chloride for $24 \mathrm{~h}$ and then reweighed (87). Percentage of moisture in the patch is calculated using the following equation (1):

$$
\text { Moisture content }(\%)=\frac{\text { Initial mass }- \text { Final mass }}{\text { Initial mass }} \times 100
$$

Moisture uptake or mass gain (88)

Mass gain in a transdermal patch usually signifies moisture uptake. To measure moisture uptake, the patch is weighed, placed in a desiccator with a saturated $\mathrm{KCl}$ solution, and incubated up to $24 \mathrm{~h}$ with $\mathrm{RH}$ maintained at about $84 \%$. The patch is then reweighed and moisture uptake is calculated using equation (2). 


$$
\text { Moisture uptake }(\%)=\frac{\text { Final mass }- \text { Initial mass }}{\text { Initial mass }} \times 100
$$

\section{Evaluation of water vapor permeability}

A natural air circulation oven is used to determine water vapor permeability (WVP) in a patch, where:

$$
W V P=W / A
$$

where water vapor permeability is expressed in $\mathrm{g} \mathrm{m}^{-2}$ per $24 \mathrm{~h}, W=$ amount of water vapor (g per $24 \mathrm{~h}$ ) permeated in the patch, and $A$ is the surface area $\left(\mathrm{m}^{2}\right)$ exposed on the patch sample (89).

\section{Drug content}

To measure the drug content of a transdermal patch, a specific area of the patch is dissolved in a specific volume of a selected solvent. The solution is shaken continuously for up to $24 \mathrm{~h}$, ultrasonicated for a specific period of time and then filtered. Drug content in the filtrate is determined using an appropriate analytical method (87).

\section{Flatness test}

A transdermal patch is cut into three longitudinal strips: one from the right side, one from the left side, and one from the center. The length of each strip is measured (90). The following equation is used for flatness determination:

$$
\text { Constriction }(\%)=\left(I_{1}-I_{2}\right) \times 100
$$

where $I_{1}=$ strip initial length, $I_{2}=$ strip final length .

\section{Stability studies}

Prepared transdermal patches are stored for six months at $40 \pm 0.5^{\circ} \mathrm{C}$ and $\mathrm{RH}$ of $75 \pm$ $5 \%$. After the six-month storage, the samples are taken out of storage at intervals of 0,30 , 60,90 , and 180 days and analyzed to determine the drug content (91).

\section{Determination of adhesive properties}

Adhesive properties can be characterized using a number of tests such as peel force tests, adhesive strength tests and tack tests. In vitro and in vivo tests can be used to characterize the adhesive properties of the drug in a transdermal preparation (82).

\section{Tack properties}

Tack is the ability of a given polymer to stick to a substrate when light pressure is applied. Tack depends on the composition and the molecular weight of the polymer. 


\section{Probe tack test}

The force required to pull a probe, far from the adhesive polymer at a fixed rate, is measured as the value of tack. The probe tack test can be used to replace the thumb test to determine the amount of force required to break the bond of the surface of a pressure sensitive adhesive in a transdermal patch (92). The force required to break the bond over specific time is plotted as force vs. time.

\section{Quick stick test/Peel tack test}

This test involves pulling an adhesive tape over the transdermal patch at an angle of $90^{\circ}$ and a speed of 12 inches/min. The tack value is the peeling force needed for breaking the bond between substrate and adhesive (93).

\section{Peel adhesion test}

Peel adhesion is the force needed to remove an adhesive polymer coating from a given substance. To measure peel adhesion, a piece of tape is applied to a plate of stainless steel backing membrane and then pulled at $180^{\circ}$ from the test substance. The force required to pull the tape is then measured. The test is performed to make sure that the adhesive does not damage the skin and that no residues are left on the skin (94).

\section{Tensile strength}

Tensile strength is measured with a tensiometer. A patch is fixed to the tensiometer assembly, the weight required to break the patch is determined, and the resultant elongation of the patch is measured (with the pointer on the instrument). The mean of three patch readings is considered to be the tensile strength of the patch (92). The tensile strength of the patch is:

$$
\text { Tensile strength }=\text { break force } / a \times b(1+\Delta L / L)
$$

where, $a=$ patch width, $b=$ patch thickness, $L=$ patch length, $\Delta L=$ patch elongation at breakage point, and break force $=$ weight $(\mathrm{kg})$ required for patch breakage.

\section{Swellability}

To determine the swellability of a transdermal patch, the sample is applied to a preweighed cover slip in a Petri dish containing $50 \mathrm{~mL}$ phosphate buffer, $\mathrm{pH}$ 7.4. Sample absorption takes place during time $t$ (usually about $30 \mathrm{~min}$ ) (95). After time $t$ has elapsed, the cover slip is removed from the Petri dish, washed and weighed. The change in mass is equal to the mass of water absorbed by the patch.

Percentage swelling $(S)$ is determined by the following equation (95).

$$
\mathrm{S}(\%)=\frac{\mathrm{W}_{\mathrm{t}}-\mathrm{W}_{0}}{\mathrm{~W}_{0}} \times 100
$$

where $S=\%$ swelling, $W_{0}=$ original mass of the patch at time zero, $W_{\mathrm{t}}=$ patch mass at time $t$ after swelling. 
In vitro drug release

An in vitro drug release evaluation experiment can give reliable indication of the rate and extent of drug release from a transdermal patch. A number of methods can be used to evaluate drug release from the transdermal formulation with an appropriate, non-rate-limiting membrane. However, alternative methods, with improved discriminative power compared to the compendial methods, may be employed (82). A number of methods can be used to evaluate drug release from a transdermal formulation (96) and they include: $i$ ) the paddle over disc (USP apparatus 5/PhEur 2.9.4.1) which is similar to the USP paddle dissolution apparatus, except that temperature is adjusted to skin temperature $\left(32 \pm 5{ }^{\circ} \mathrm{C}\right)$ and a disc or cell containing the formulation is immersed at the bottom of the vessel; ii) the cylinder modified United States Pharmacopeia (United States Pharmacopeial Convention, Inc.) (USP) basket (USP apparatus 6 / PhEur 2.9.4.3) which is similar to the USP basket type dissolution apparatus method, except for a hollow cylinder immersed in medium and temperature maintained at $32 \pm 5{ }^{\circ} \mathrm{C}$; iii) the reciprocating disc (USP apparatus 7) method in which the formulation is placed into holders and oscillated in small volumes of buffer medium; iv) paddle over extraction cell method (PhEur 2.9.4.2) may also be used. Besides, diffusion cells include the Franz-diffusion cell and its modification the Keshary-Chien cell widely used to evaluate drug release from the transdermal formulation.

Mathematical models that describe the kinetics of drug release from a transdermal patch include Higuchi, first order, zero order, and Peppas and Korsenmeyer models. After data are collected and introduced into these models, the model that fits the data best is used to determine the mechanism of kinetic drug release (97). According to the European Medicines Agency Guidelines on quality of transdermal patches issued by the Committee for Medicinal Products for Human Use, at least 3 sampling time points are recommended (82).

\section{Ex vivo skin permeation studies}

Ex vivo skin permeation studies might not be indicative of the in vivo release assessment, but may be considered a valuable measure of product quality, reflecting the thermodynamic activity of the active substance in the product. Ex vivo skin permeation studies should be consistent throughout the shelf-life of the transdermal preparation (82). The ex vivo permeation studies are performed using a vertical diffusion cell, commonly called the Franz diffusion cell. The ex vivo permeation assessment carried out using two compartments for diffusion, an upper compartment with the diffusion area of $1.54 \mathrm{~cm}^{2}$ and an inner compartment with a volume of up to $10 \mathrm{~mL}$ (98). An animal biological membrane such as pig ear skin or rat's skin can be used and placed between the two compartments for the permeation study. A phosphate buffer solution of $\mathrm{pH} 7.5$ is usually used as acceptor medium. For the receptor compartment of the diffusion cell, the receptor solution is maintained at $32 \pm 0.5^{\circ} \mathrm{C}$ under constant stirring using magnetic rods (99). The patch is placed between the upper and inner compartments mounted so that the drug releasing surface faces the receptor side. The inner compartment buffer medium is subjected to continuous stirring at a constant rate. Samples of about $500 \mu \mathrm{L}$ are usually taken over specific intervals. When a sample is taken, it is replaced with a similar volume of buffer. Collected samples are further diluted and measured using a proper analytical HPLC method. Drug permeation is measured at regular intervals, and volume vs. time plots are constructed. 


\section{Skin irritation study}

Skin irritation potential of different transdermal patches can be evaluated either by visual inspection of erythema and edema using the PII test or examined microscopically by a light microscope for any histopathological changes. Albino rats of average weight up to $230 \mathrm{~g}$ can be used to test transdermal patches for skin irritation. Patches applied over an area of $8.1 \mathrm{~cm}^{2}$ of the rat back after it is cleaned with rectified spirit and shaved $24 \mathrm{~h}$ prior to the experiment (100). The patch is applied for $24 \mathrm{~h}$, then removed and the area is cleaned with a disinfectant swab. Inspection is carried out visually on the sites of application for any possible changes in terms of skin erythema and edema. Draize scale can be used to score the changes involving erythema and edema between 0 and 4 (101). This is rated based on the degree of severity of skin reactions (101). PII is calculated according to the following equation:

PII $=\{$ Sum of erythema grade on many days + Sum of edema grade on a number of days\}/Number of animals (102).

\section{CONCLUSIONS}

On the basis of the obtained review, this article provides valuable literature on transdermal patches, structural components, characterization and assessment tools required for the preparation, development and clinical performance of the various types of patches.

\section{REFERENCES}

1. L. Zhang and S. Mao, Application of quality by design in the current drug development, As. J. Pharm. Sci. 12 (2017) 1-8; https://doi.org/10.1016/j.ajps.2016.07.006

2. M. R. Prausnitz and R. Langer, Transdermal drug delivery, Nat. Biotechnol. 26 (2008) 1261-1268; https://doi.org/10.1038/nbt.1504

3. M. J. Tsai, I. J. Lu, Y. S. Fu, Y.P. Fang, Y. B. Huang and P. C. Wu, Nanocarriers enhance the transdermal bioavailability of resveratrol: In-vitro and in-vivo study, Colloids Surf. B Biointerfaces 148 (2016) 650-656; https://doi.org/10.1016/j.colsurfb.2016.09.045

4. A. Simon and M. I. Amaro, A. M. Healy, L. M. Cabral and V. P. de Sousa, Comparative evaluation of rivastigmine permeation from a transdermal system in the Franz cell using synthetic membranes and pig ear skin with in vivo-in vitro correlation, Int. J. Pharm. 512 (2016) 234-241; https://doi. org/10.1016/j.jpharm.2016.08.052

5. E. M. Pridgen, F. Alexis and O. C. Farokhzad, Polymeric nanoparticle drug delivery technologies for oral delivery applications, Expert Opin. Drug. Deliv. 12 (2015) 1459-1473; https://doi.org/10.1517/17 425247.2015.1018175

6. M. Arafat, Approaches to achieve an oral controlled release drug delivery system using polymers: a recent review, Int. J. Pharm. Pharm. Sci. 7 (2015) 16-21.

7. R. Gannu, Y. V. Vishnu, V. Kishan and Y. M. Rao, Development of nitrendipine transdermal patches: in vitro and ex vivo characterization, Curr. Drug Deliv. 4 (2007) 69-76.

8. M. Arafat, Bilosomes as a Drug Delivery System, in Thesis, Doctor of Philosophy, University of Otago, NZ, (2012); http://hdl.handle.net/10523/2157

9. M. N. Pastore, Y. N. Kalia, M. Horstmann and M. S Roberts, Transdermal patches: history, development and pharmacology, Br. J. Pharmacol. 172 (2015) 2179-2209; https://doi.org/10.1111/bph.13059 
10. M. B. Brown, G. P. Martin, S. A. Jones and F. K. Akomeah, Dermal and transdermal drug delivery systems: Current and future prospects, Drug Del. 13 (2008) 175-187; https://doi. org/10.1080/10717540500455975

11. K. S. Paudel, M. Milewski, C. L. Swadley, N. K Brogden, P. Ghosh and A. L. Stinchcomb, Challenges and opportunities in dermal/transdermal delivery, Ther. Deliv. 1 (2010) 109-131.

12. G. A. Van Norman, Drugs, Devices, and the FDA: Part 2: An overview of approval processes: FDA approval of medical devices, JACC: Bas. Transl. Sci. 1 (2016) 277-287; https://doi.org/10.1016/j. jacbts.2016.03.009

13. M. Isaac and C. Holvey, Transdermal patches: the emerging mode of drug delivery system in psychiatry, Ther. Adv. Psychopharmacol. 2 (2012) 255-263; https://doi.org/10.1177/2045125312458311

14. A. Z. Alkilani, M. T. C. McCrudden and R. F. Donnelly, Transdermal drug delivery: innovative pharmaceutical developments based on disruption of the barrier properties of the stratum corneum, Pharmaceutics 7 (2015) 438-470; https://doi.org/10.3390/pharmaceutics7040438

15. M. Murphy and A. J. Carmichael, Transdermal drug delivery systems and skin sensitivity reactions. Incidence and management, Am. J. Clin. Dermatol. 1 (2000) 361-368.

16. P. Karandea and S. Mitragotrib, Enhancement of transdermal drug delivery via synergistic action of chemicals, Biochim. Biophys. Acta 1788 (2009)2362-2373; https://doi.org/10.1016/j.bbamem.2009.08.015

17. J. Suksaeree, C. Monton, F. Madaka, T. Chusut, W. Saingam, W. Pichayakorn and P. Boonme, Formulation, physicochemical characterization, and in vitro study of chitosan/HPMC blends-based herbal blended patches, AAPS Pharm. Sci. Tech. 16 (2015) 171-181; https://doi.org/10.1208/s12249-0140216-6

18. N. S. Chandrashekar and R. H. S. Rani, Physicochemical and pharmacokinetic parameters in drug selection and loading for transdermal drug delivery, Indian J. Pharm. Sci. 70 (2008) 94-96; https://doi. org/10.4103/0250-474X.40340

19. M. Arafat, The effect of intestinal bile on the stability of lipid-based vesicular system used as oral drug carriers, Glob. Drug Therap. 2 (2016) 1-2; https://doi.org/10.15761/GDT.1000109

20. J. Suksaereeab, L. Charoenchaib, F. Madakab, C. Montonb, A. Sakunpak, T. Charoonratana and W. Zingiber, Cassumunar blended patches for skin application: Formulation, physicochemical properties, and in vitro studies, Asian J. Pharm. Sci. 10 (2015)341-349; https://doi.org/10.1016/j.ajps.2015.03.001

21. A. C. Willams and B. W. Barry, Penetration enhancers, Adv. Drug. Del. Rev. 56 (2004) 603-618.

22. S. D. Saoji, S. C. Atram, P. W. Dhore, P. S. Deole, N. A. Raut and V. S. Dave, Influence of the component excipients on the quality and functionality of a transdermal film formulation, AAPS Pharm. Sci. Tech. 16 (2015) 1344-1356; https://doi: 10.1208/s12249-015-0322-0

23. M. Imani, F. Lahooti-Fard, S. M. Taghizadeh and M Takrousta, Effect of adhesive layer thickness and drug loading on estradiol crystallization in a transdermal drug delivery system, AAPS Pharm. Sci. Tech. 11 (2010) 1268-1275; https://doi.org/10.1208/s12249-010-9494-9

24. S. Dhiman, T. G. Singh and A. K. Rehni, Transdermal patches: A recent approach to new drug delivery system, Int. J. Pharm. Pharm. Sci. 3 (2011) 26-34.

25. S. Rani, K. Saroha, N. Syan and P. Mathur, Transdermal patches a successful tool in transdermal drug delivery system: An overview, Der Pharm. Sinica 2 (2011) 17-29.

26. B. Berner and V. A. John, Pharmacokinetic characterization of transdermal delivery system, J. Clin. Pharmacol. 26 (1994) 121-134.

27. S. Mutalik and N. Udupa, Pharmacological evaluation of membrane-moderated transdermal system of glipizide, Clin. Exp. Pharmacol. Physiol. 33 (2006) 17-26.

28. C. L. Stevenson, J. T. Jr. Santini and R. Langer, Reservoir-based drug delivery systems utilizing microtechnology, Adv. Drug Deliv. Rev. 64 (2012) 1590-1602; https://doi.org/10.1016/j.addr.2012.02.005

29. P. J. Hughes, M. K. Freeman and T. M. Wensel, Appropriate use of transdermal drug delivery systems, J. Nurs. Edu. Pract. 3 (2013) 129-138. 
30. S. Cherukuri, U. R. Batchu, K. Mandava, V. Cherukuri, K. R. Ganapuram, Formulation and evaluation of transdermal drug delivery of topiramate, Int. J. Pharm. Investig. 7 (2017) 10-17; https://doi. org/10.4103/jphi.JPHI_35_16

31. E. Abd, S. A. Yousef, M. N. Pastore, K. Telaprolu, Y. H. Mohammed, S. Namjoshi, J. E. Grice and M. S. Roberts, Skin models for the testing of transdermal drugs, Clin. Pharmacol. 8 (2016) 163-176; https:// doi.org/10.2147/CPAA.S64788

32. A. Z. Alkilani, M. T. C. McCrudden and R. F. Donnelly, Transdermal drug delivery: innovative pharmaceutical developments based on disruption of the barrier properties of the stratum corneum, Pharmaceutics 7 (2015) 438-470; https://doi.org/10.3390/pharmaceutics7040438

33. H. Trommer and R. H. H. Neubert, Overcoming the stratum corneum: the modulation of skin penetration, Skin Pharmacol. Physiol. 19 (2006) 106-121; https://doi.org/10.1159/000091978

34. S. S. Davis and L. Illum, Drug Delivery Systems for Challenging Molecules, Int. J. Pharm. 176 (1998) $1-8$.

35. A. Ahmed, N. Karki, R. Charde, M. Charde and B. Gandhare, Transdermal drug delivery systems: An overview, Int. J. Biomed. Adv. Res. 2 (2010) 38-56.

36. S. R. W. Baker and J. Heller, Material Selection for Transdermal Delivery Systems, in Transdermal Drug Delivery: Developmental Issues and Research Initiatives (Eds. J. Hadgraft and R. H. Guys), Marcel Dekker, Inc., New York 1989, pp. 293-311.

37. M. Guyot and F. Fawaz, Design and in vitro evaluation of adhesive matrix for transdermal delivery of propranolol, Int. J. Pharm. 204 (2000) 171-182.

38. Ł. Zimmer, R. Kasperek and E. Poleszak, Modern polymers in matrix tablets technology, Polim. Med. 44 (2014)189-196.

39. M. Guyot and F. Fawaz, Design and in vitro evaluation of adhesive matrix for transdermal delivery of propranolol, Int. J. Pharm. 204 (2000) 171-182.

40. A. F. El-Kattan, C. S. Asbill and B. B. Michniak, The effect of terpene enhancer lipophilicity on the percutaneous permeation of hydrocortisone formulated in HPMC gel systems, Int. J. Pharm. 198 (2000) 179-189.

41. R. Sutinen, P. Paronen, V. Saano and A. Urtti, Water-activated, $\mathrm{pH}$-controlled patch in transdermal administration of timolol: II. Drug absorption and skin irritation, Eur. J. Pharm. Sci. 11 (2000) 25-31.

42. H. Iwase, J. I. Sudo, J. Terui, K. Kakuno, T. Watanabe, K. Takayama and T. Nagai, Transdermal absorption of L-dopa from a new system composed of two separate layers of L-dopa and hydrogel in rats, Drug Dev. Ind. Pharm. 26 (2000) 755-759.

43. M. K. Kim, H. Zhao, C. H. Lee and D. D. Kim, Formulation of a reservoir-type testosterone transdermal delivery system, Int. J. Pharm. 219 (2001) 51-59.

44. H. Gabiga, K. Cal and S. Janicki, Effect of penetration enhancers on isosorbide dinitrate penetration through rat skin from a transdermal therapeutic system, Int. J. Pharm. 199 (2000) 1-6.

45. S. Ohmori, T. Hayash, M. Kawase, S. Saito, K. Sugibayashi and Y. Morimoto, Transdermal delivery of the potent analgesic dihydroetorphine: kinetic analysis of skin permeation and analgesic effect in the hairless rat, J. Pharm. Pharmacol. 52 (2000) 1437-1449.

46. T. Pongjanyakul, S. Prakongpan and A. Priprem, Permeation studies comparing cobra skin with human skin using nicotine transdermal patches, Drug Dev. Ind. Pharm. 26 (2000) 635-642.

47. S. M. Al-Saidan,Y. S. R. Krishnaiah, D. V. Chandrasekhar, J. K. Lalla, B. Rama, B. Jayaram and P. Bhaskar, Formulation of an HPMC gel drug reservoir system with ethanol-water as a solvent system and limonene as a penetration enhancer for enhancing in vitro transdermal delivery of nicorandil, Skin Pharmacol. Physiol. 17 (2004) 310-320.

48. Y. S. Krishnaiah, P. Bhaskar and V. Satyanarayana, Penetration-enhancing effect of ethanol-water solvent system and ethanolic solution of carvone on transdermal permeability of nimodipine from HPMC gel across rat abdominal skin, Pharm. Dev. Technol. 9 (2004) 63-74. 
49. Y. Tanwar, C. Chauhan and A. Sharma, Development and evaluation of carvedilol transdermal patches, Acta Pharm. 57 (2007) 151-159.

50. A. Wahid, B. Sridhar and S. Shivakumar, Preparation and evaluation of transdermal drug delivery system of etoricoxib using modified chitosan, Indian J. Pharm. Sci. 70 (2008) 455-460.

51. B. Winblad and J. C. Machado. Use of rivastigmine transdermal patch in the treatment of Alzheimer's disease, Expert Opin. Drug Deliv. 5 (2008) 1377-1386.

52. C. Ren, L. Fang, L. Ling, Q. Wang, S. Liu, L. Zhao and Z. He, Design and in vivo evaluation of an indapamide transdermal patch, Int. J. Pharm. 370 (2009) 129-135.

53. S. Jayaprakash, S. M. Halith, P. M. Firthouse and N. M. Yasmin, Preparation and evaluation of celecoxib transdermal patches, Pak. J. Pharm. Sci. 23 (2010) 279-283.

54. Y. C. Ah, J. K. Choi, Y. K. Choi, H. M. Ki and J. H. Bae, A novel transdermal patch incorporating meloxicam: in vitro and in vivo characterization, Int. J. Pharm. 385 (2010) 12-19.

55. P. Anitha, S. Ramkanth, M. T. Saleem, K. Umasankari, B. P. Reddy and M. Chetty, Preparation, invitro and in-vivo characterization of transdermal patch containing glibenclamide and atenolol: a combinational approach, Pak. J. Pharm. Sci. 24 (2011) 155-163.

56. D. M. Panchaxari, S. Pampana, T. Pal, B. Devabhaktuni and A. K. Aravapalli, Design and characterization of diclofenac diethylamine transdermal patch using silicone and acrylic adhesives combination, Daru 21 (2013) 6; https://doi.org/10.1186/2008-2231-21-6

57. H. M. Wolff, Optimal process design for the manufacture of transdermal drug delivery systems, Pharm. Sci. Technol. Today. 3 (2000) 173-181.

58. L. Bromberg, Crosslinked poly(ethylene glycol) networks as reservoirs for protein delivery, J. Appl. Polym. Sci. 59 (1996) 459-466.

59. P. Costa, D. C. Ferreira, R. Morgado and J. S. Lobo, Design and evaluation of a lorazepam transdermal delivery system, Drug Dev. Ind. Pharm. 23 (1997) 939-944.

60. P. Minghetti, F. Cilurzo and L. Montanari, Evaluation of adhesive properties of patches based on acrylic matrices, Drug Dev. Ind. Pharm. 25 (1999) 1-6.

61. P. R. Rao and P. V. Diwan, Formulation and in vitro evaluation of polymeric films of diltiazem hydrochloride and indomethacin for transdermal administration, Drug Dev. Ind. Pharm. 24 (1998) 327-336.

62. S. S. Baek and S. H. Hwang, Eco-friendly UV-curable pressure sensitive adhesives containing acryloyl derivatives of monosaccharides and their adhesive performances, Int. J. Adhes. Adhes. $\mathbf{7 0}$ (2016) 110-116; https://doi.org/10.1016/j.ijadhadh.2016.06.002

63. S. Banerjee, P. Chattopadhyay, A. Ghosh, P. Datta and V. Veer, Aspect of adhesives in transdermal drug delivery systems, Int. J. Adhes. Adhes. 50 (2014) 70-84; https://doi.org/10.1016/j.ijadhadh.2014.01.001

64. C. Fang, Y. Jing, Y. Zong and Z. Lin, Effect of N,N-dimethylacrylamide (DMA) on the comprehensive properties of acrylic latex pressure sensitive adhesives, Int. J. Adhes. Adhes. 71 (2016) 105-111; https://doi.org/10.1016/j.ijadhadh.2016.09.003

65. V. G. Kadajji and G. V. Betageri. Water soluble polymers for pharmaceutical applications, Polymers 3 (2011) 1972-2009; https://doi.org/10.3390/polym3041972

66. I. Benedek, M. M. Feldstein, N. Willenbacher and O. V. Lebedeva, Polyisobutene-Based PressureSensitive Adhesives. Technology of Pressure-Sensitive Adhesives and Products, CRC Press; 2008. p. 4-1-4-18.

67. X. Tong, Q. Wang, H. X. Wang, X. H. Li, W. Wu and X. Y. Chey, Fabrication of pH sensitive amphiphilic hot-melt pressure sensitive adhesives for transdermal drug delivery system, Int. J. Adhes. Adhes. 48 (2014) 217-223; https://doi.org/10.1016/j.ijadhadh.2013.09.025

68. D. J. Lyman and B. H. Loo, New synthetic membranes for dialysis. IV. A copolyether-urethane membrane system, J. Biomed. Mater. Res. 1 (1967) 17-26. 
69. V. Stannett, W. Koros, D. Paul, H. Lonsdale and R. Baker, Recent Advances in Membrane Science and Technology, in Advances in Polymer Sciences, Vol. 32, Chemistry, Springer Verlag, Berlin 1979, pp. 69121.

70. D. G. Maillard-Salin, P. Becourt and G. Couarraze, Physical evaluation of a new patch made of a progestomimetic in a silicone matrix, Int. J. Pharm. 199 (2000) 29-38.

71. D. G. Maillard-Salin, P. Becourt and G. Couarraze, A study of the adhesive-skin interface: correlation between adhesion and passage of a drug, Int. J. Pharm. 200 (2000) 121-126.

72. C. D. Ebert, W. Heiber, R. Andriola and P. Williams, Development of a novel transdermal system design, J. Control. Release. 6 (1987) 107-111.

73. A. Flo, T. Cambras, A. Díez-Noguera and A. Calpena, Melatonin pharmacokinetics after transdermal administration changes according to the time of the day, Eur. J. Pharm. Sci. 96 (2017) 164-170; https://doi.org/10.1016/j.ejps.2016.09.020

74. I. Som, K. Bhatia and M. Yasir, Status of surfactants as penetration enhancers in transdermal drug delivery, J. Pharm. Bioallied Sci. 4 (2012) 2-9; https://doi.org/10.4103/0975-7406.92724

75. Y. Chen, P. Quan, X. Liu, M. Wang and L. Fang, Novel chemical permeation enhancers for transdermal drug delivery, Asian J. Pharm. Sci. 9 (2014) 51-64.

76. Q. D. Pham, S. Björklund, J. Engblom, D. Topgaard and E. Sparr, Chemical penetration enhancers in stratum corneum - Relation between molecular effects and barrier function, J. Control. Release 232 (2016) 175-187; https://doi.org/10.1016/j.jconrel.2016.04.030

77. G. El Maghraby, A. C. Williams and B. Barry, Interactions of surfactants (edge activators) and skin penetration enhancers with liposomes, Int. J. Pharm. 276 (2004) 143-161.

78. M. Arafat, C. Kirchhoefer, M. Mikov, M. Sarfraz and R. Löbenberg, Nanosized liposomes containing bile salt: A vesicular nanocarrier for enhancing oral bioavailability of BCS class III drug, J. Pharm. Pharm. Sci. 20 (2017) 305-318; https://doi.org/10.18433/J3CK88

79. M. Arafat, C. Kirchhoefer and M. Mikov, Mixed micelles loaded with bile salt: an approach to enhance intestinal transport of the BCS class III drug cefotaxime in rats, Eur. J. Drug Metab. Pharmacokinet. 42 (2017) 635-645; https://doi.org/10.1007/s13318-016-0375-9

80. T. E. G. K. Murthy and V. S. Kishore, Effect of casting solvent and polymer on permeability of propranolol hydrochloride through membrane controlled transdermal drug delivery system, Indian J. Pharm. Sci. 69 (2007) 646-650; https://doi.org/10.4103/0250-474X.38469

81. A. Alexander, S. Dwivedi, T. K. Giri, S. Saraf and D. K. Tripathi, Approaches for breaking the barriers of drug permeation through transdermal drug delivery, J. Control. Release 164 (2012) 26-40; https://doi.org/10.1016/j.jconrel.2012.09.017

82. Guideline on quality of transdermal patches. European Medicines Agency, Committee for Medicinal Products for Human Use (2014) 1-27. EMA/CHMP/QWP/608924/2014

83. H. Lim and S. W. Hoag, Plasticizer effects on physical-mechanical properties of solvent cast Soluplus ${ }^{\circledR}$ films, AAPS Pharm. Sci. Tech 14 (2013) 903-910; https://doi.org/10.1208/s12249-013-9971-z

84. M. Arafat, Z. Ahmed and O. Arafat, Comparison between generic drugs and brand name drugs from bioequivalence and thermoequivalence prospective, Int. J. Pharm. Pharm. Sci. 9 (2017) 1-4.

85. M. Bharkatiya, R. Nema and M. Bhatnagar, Designing and characterization of drug free patches for transdermal application, Int. J. Pharm. Sci. Drug Res. 2 (2012) 35-39.

86. K. C. Garala, A. J. Shinde and P. H. Shah, Formulation and in-vitro characterization of monolithic matrix transdermal systems using HPMC/Eudragit S 100 polymer blends, Int. J. Pham. Pharm. Sci. 1 (2009) 108-120.

87. J. M. Prosser, B. E. Jones and L. Nelson, Complications of oral exposure to fentanyl transdermal delivery system patches, J. Med. Toxicol. 6 (2010) 443-447. 
88. J. Singh, K. Tripathi and T. Sakya, Effect of penetration enhancers on the in vitro transport of ephedrine through rat skin and human epidermis from matrix based transdermal formulations, Drug Dev. Ind. Pharm. 19 (1993) 1623-1628.

89. N. Maftoona, H. S. Ramaswamy and M. Marcotte, Evaluation of factors affecting barrier, mechanical and optical properties of pectin-based films using response surface methodology, J. Food. Process Eng. 30 (2007) 539-563; https://doi.org/10.1111/j.1745-4530.2007.00123.x

90. A. Singh and A. Bali, Formulation and characterization of transdermal patches for controlled delivery of duloxetine hydrochloride, J. Anal. Sci. Technol. 7 (2016) 25; https://doi.org/10.1186/s40543016-0105-6

91. J. Wiechers, Use of chemical penetration enhancers in transdermal drug delivery - possibilities and difficulties, Acta Pharm Nord. 4 (1992) 123.

92. S. Banerjee, P. Chattopadhyay, A. Ghosh, P. Datta and V. Veer, Aspect of adhesives in transdermal drug delivery systems, Int. J. Adhes. Adhes. 50 (2014) 70-84.

93. A. M. Wokovich, S. Prodduturi, W. H. Doub, A. S. Hussain and L. F. Buhse, Transdermal drug delivery system (TDDS) adhesion as a critical safety, efficacy and quality attribute, Eur. J. Pharm. Biopharm. 64 (2006) 1-8.

94. A. J. Steven-Fountain, A. G. Atkins, G. Jeronimidis, J. F. V. Vincent, D. F. Farrar and R. A. Chivers, The effect of flexible substrates on pressure-sensitive adhesive performance, Int. J. Adhes. Adhes. 22 (2002) 423-430.

95. G. Thakur, A. Singh and I. Singh, Formulation and evaluation of transdermal composite films of chitosan-montmorillonite for the delivery of curcumin, Int. J. Pharm. Investig. 6 (2016) 23-31; https:// doi.org/10.4103/2230-973X.176468

96. T. Kamal, M. Sarfraz, M. Arafat, M. Mikov and N Rahman, Cross-linked guar gum and sodium borate based microspheres as colon-targeted anticancer drug delivery systems for 5-fluorouracil, Pak. J. Pharm. Sci. 30 (2017) 2329-2336.

97. O. A. Hanbali, R. Hamed, M. Arafat, Y. Bakkour, H. Matubsi, R. Mansour, Y. Bataineh, M. Aldhoun, M. Sarfraz and A. K. Yousef Dardas, Formulation and evaluation of diclofenac controlled release matrix tablets made of HPMC and Poloxamer 188 polymer: An assessment on mechanism of drug release, Pak. J. Pharm. Sci. 31 (2018) 345-351.

98. T. Z. Marques, R. Santos-Oliveira, L. B. de Siqueira, V. S. Cardoso, Z. M. de Freitas, R. C. Barros, A. L. Villa, M. S. Monteiro, E. P. Santos and E. Ricci-Junior, Development and characterization of a nanoemulsion containing propranolol for topical delivery, Int. J. Nanomedicine 13 (2018) 2827-2837; https://doi.org/10.2147/IJN.S164404

99. C. S. Cerqueira-Coutinho, V. E. De Campo, A. L. Rossi, V. F. Veiga, C. Holandino, Z. M. Freitas, E. Ricci-Junior, C. R. Mansur, E. P. Santos and R. Santos-Oliveira, Comparing in vivo biodistribution with radiolabeling and Franz cell permeation assay to validate the efficacy of both methodologies in the evaluation of nanoemulsions: a safety approach, Nanotechnology 27 (2016) 015101; https://doi. org/10.1088/0957-4484/27/1/015101

100. J. Wang, Y. Wei, Y. R. Fei, L. Fang, H. S. Zheng, C. F. Mu, F. Z. Li and Y. S. Zhang, Preparation of mixed monoterpenes edge activated PEGylated transfersomes to improve the in vivo transdermal delivery efficiency of sinomenine hydrochloride, Int. J. Pharm. 533 (2017) 266-274; https://doi. org/10.1016/j.ijpharm.2017.09.059

101. I. I. Abu Hashim, N. F. Abo El-Magd, A. R. El-Sheakh and M. F. Hamed, Pivotal role of Acitretin nanovesicular gel for effective treatment of psoriasis: ex vivo-in vivo evaluation study, Int. J. Nanomedicine 13 (2018) 1059-1079; https://doi.org/10.2147/IJN.S156412

102. A. Manosroi, C. Chankhampan, W. Manosroi and J. Manosroi, Transdermal absorption enhancement of papain loaded in elastic niosomes incorporated in gel for scar treatment, Eur. J. Pharm. Sci. 48 (2013) 474-483; https://doi.org/10.1016/j.ejps.2012.12.010 